Research Article

\title{
Comparison of Different Analyzing Techniques in Identifying Rainfall Trends for Colombo, Sri Lanka
}

\author{
Anushka Perera, Thilini Ranasinghe, Miyuru Gunathilake, and Upaka Rathnayake $\mathbb{D}$ \\ Department of Civil Engineering, Faculty of Engineering, Sri Lanka Institute of Information Technology (SLIIT), \\ Malabe, Sri Lanka \\ Correspondence should be addressed to Upaka Rathnayake; upakasanjeewa@gmail.com
}

Received 5 May 2020; Revised 8 August 2020; Accepted 24 August 2020; Published 1 September 2020

Academic Editor: Panagiotis Nastos

Copyright (C) 2020 Anushka Perera et al. This is an open access article distributed under the Creative Commons Attribution License, which permits unrestricted use, distribution, and reproduction in any medium, provided the original work is properly cited.

\begin{abstract}
Identifying rainfall trends in highly urbanized area is extremely important for various planning and implementation activities, including designing, maintaining and controlling of water distribution networks and sewer networks and mitigating flood damages. However, different available methods in trend analysis may produce comparable and contrasting results. Therefore, this paper presents an attempt in comparing some of the trend analysis methods using one of the highly urbanized areas in Sri Lanka, Colombo. Recorded rainfall data for 10 gauging stations for 30 years were tested using the MannKendall test, Sen's slope estimator, Spearman's rho test, and innovative graphical method. Results showcased comparable findings among three trend identification methods. Even though the graphical method is easier, it is advised to use it with a proper statistical method due to its identification difficulties when the data scatter has some outliers. Nevertheless, it was found herein that Colombo is under a downward rainfall trend in the month of July where the area receives its major rainfall events. In addition, the area has several upward rainfall trends over the minor seasons and in the annual scale. Therefore, the water management activities in the area have to be revisited for a sustainable use of water resources.
\end{abstract}

\section{Introduction}

Climate change is a multidimensional phenomenon, which adversely impacts many social, environmental, and economic aspects [1]. It has been revealed that there is a clear relationship between biological systems to the ongoing climate change. Therefore, many researchers identified that the climate change is already affecting the living systems [2]. Visible increments in precipitation can be seen in some parts of the world, and this can well be due to the ongoing climate change. Some of the areas in North and South America, northern Europe, and northern and central Asia have shown the increasing precipitation trends in precipitation records, and thus the previous statement was well proved [3]. However, decreasing precipitation trends are also observed in some of the areas and specifically in Sahel [4], the Mediterranean, southern Africa, and southern Asia [5].
Due to these climate changes and variations, frequent extreme climatic disasters, such as flood and droughts, have occurred. They have resulted in severe adverse impacts on infrastructure, dams, urban drainage systems, and livelihood of human, animals, and vegetation [6, 7]. It has been found out that multiday rainfall events have massively contributed to the extreme floods [7-9]. Due to inability of predicting the climate patterns, the flood defenses have become less efficient.

Analyzing long return-period rainfall events can be done using standard regional frequency analysis, which will produce generalized extreme value growth curves [10]. However, most of the studies have analyzed the trends in global climate change to a certain extent through different statistical models. Nevertheless, less attention was given to climate change impacts at regional or local scales throughout the past decades. The limited availability of long-term instrumental data [11] and given the uncertainties in modeling 
procedures are demotivated [12], some of the researchers do not analyze the weather patterns in different regions inside one country. Analyzing seasonal, decadal, or multidecadal trends can be challenging due to this unavailability of historic long-term weather records.

Kosanic et al. [13] discussed the climate change variation using present and historic climate data, and it was mentioned that the limited availability of past rainfall records is one of the major concerns of the researchers. They further urged the need of these data in identifying the key risks and for the mitigation of impacts due to climatic changes. Institutional gaps, poor data management, and destruction of hydrological equipment by floods have resulted gaps in hydrological time series [14]. Therefore, incorrect estimations on various natural disasters are possible. In addition, Brunet and Jones [11] stated that limited availability of longterm and qualitative historical climate records has limited the ability to understand the detection and the prediction of global climate variability. Therefore, undertaking an integrated data rescue (DARE) is an essential task. However, various mathematical models are being used to complete the missing data in the climate series [15]. These data can either be derived from satellites or from global model-based reanalysis.

The literature shows several trend analysis studies in the context of Sri Lanka. Most of them were in the direction of nonparametric tests. Alahacoon et al. [16] indicated that there is an increasing trend in rainfall indices when considering the time series rainfall data in 11 river basin areas selected throughout the country. They have further proved that the accuracy of these results from the obtained satellite images for the considered locations. Jayawardene et al. [17] concluded that statistically significant increasing trends in rainfall are possible, including Colombo, Sri Lanka. They have tested rainfall data from 15 meteorological stations all over the country. However, they have concluded that some of the places are not under significant rainfall trends. Herath and Ratnayake [18] summarized the seasonal rainfall trends and its impact to the landslides in the country. They have identified a strong relationship with the increased spatial variations in rainfall and location of landslides. Jayawardena et al. [19], Navendrakumar et al. [20], Malmgren et al. [21], and Thevakaran et al. [22] are few of the examples of the literature for rainfall trend analysis in Sri Lanka. However, there is little research on comparing different methods in the detection of rainfall trends to Sri Lanka. Nevertheless, Nissansala et al. [23] have presented a comparative study on rainfall trends using innovative trend analysis (ITAgraphical method) and MannKendall method. The work is interesting as they have sound conclusions on the two methods. In addition, Rathnayake [24] has presented a similar study to two catchments in Sri Lanka, and comparable results were presented from that study.

However, a detailed comparative analysis on various trend analysis methods to Sri Lanka is yet to be presented. Therefore, the aim of this paper is to analyze and compare the instrumental rainfall data in Colombo district obtained from historical weather records. This is timely important, being the capital of the country, Colombo is under many issues related to climate, natural disasters, and urbanization. The comparative analysis was carried to several rainfall scales varying on monthly, seasonal, and annual basis. The Mann-Kendall test, one of the long-established trend analysis test methods, Spearman's rho test, which is a rankbased nonparametric method, and finally the graphical method in rainfall trend analysis have been used as trend analyzing methods in this analysis. The results obtained from each method were compared to have a clear idea on the accuracy of applying them for the analysis.

In addition, this research will provide a clear understanding of climatic changes over Colombo district and will benefit to the urban system, population, and services they support. It will be helpful in planning and development of those activities without any negative impact from storm surges, flooding, and urban heat island effects, especially considering the fact that Colombo is one of the major commercial cities in the region.

\section{Homogeneity Tests for Rainfall Data Series}

Outcomes of a climatic data trend analysis solely depend on the quality of the data series used for the analysis. Hence, the reliability factor of these data is highly vital for the study. Thus, prior to a potential trend analysis, homogeneity of the climatic data was checked [25-29]. Validation of the climatic data recorded at the same location at the same time of the particular day can be done by carrying a homogeneity test [25, 30]. Different tests, including Pettitt's test, SNHT, Buishand's test, and von Neumann's test, were used to test the homogeneity of the climatic data series by many researchers [25, 30-34].

\section{MannKendall Test}

The MannKendall test is famous among most of the nonparametric tests used in identification of climatic trends. The test is treated to be one of the robust tests used by many researchers [35-38]. Mann in 1945 introduced this test for analyzing trends; however, it was further implemented in 1975 [39]. Hirsch et al. [40] further improved the nonparametric test by adding seasonality effect. Monotonic positive or negative trends are detected by the MannKendall test while the score for each season is computed through the seasonal MannKendall test [41, 42]. The MannKendall statistic $S$ is given by the following equation:

$$
\begin{array}{r}
S=\sum_{i=1}^{n-1} \sum_{j=i+1}^{n} \operatorname{sgn}\left(x_{j}-x_{i}\right), \\
\operatorname{sgn}\left(x_{j}-x_{i}\right)= \begin{cases}+1, & >\left(x_{j}-x_{i}\right), \\
0, & =\left(x_{j}-x_{i}\right), \\
-1, & <\left(x_{j}-x_{i}\right),\end{cases}
\end{array}
$$

where $x_{i}$, and $x_{j}$ are monthly, seasonal, and annual data values. From equations ( 1 and 2 ), it is visible that $S$ is independent of absolute values of data and dependent on their directional change for a given time period. The variance of $S$ 
is given by equation (3), and test statistic $Z_{c}$ given in equation (4) is formulated using $S$ :

$$
\begin{aligned}
\operatorname{Var}(S) & =\frac{n(n-1)(2 n+5)-\sum_{i=1}^{m} t_{i}(i)(i-1)(2 i+5)}{18}, \\
Z_{c} & = \begin{cases}\frac{S-1}{\sqrt{\operatorname{Var}(S)},} & S>0, \\
0, & S=0, \\
\frac{S+1}{\sqrt{\operatorname{Var}(S)}}, & S<0,\end{cases}
\end{aligned}
$$

which is then tested with the two-tailed test using an adequate significance level $\alpha$. In this paper, significance levels of $\alpha=0.05$ and 0.01 were used, and two-tailed test was carried out with the hypothesis $H_{0}$, which defines that there is no trend in the series and $H_{1}$, which defines a trend in the series at the chosen significance level $\alpha . Z_{c}$ follows the standard normal distribution, a strong $Z_{c}$ score indicates a significant trend at chosen $\alpha$, while negative and positive $Z_{c}$ indicates an upward or downward trend for the data period.

\section{Spearman's Rho Test}

Spearman's rho test is another nonparametric trend analysis technique, which is based on ranks and it can be used as a comparable test to the MannKendall test. Similar to the MannKendall test, $H_{0}$ defines that there is no trend in the series, while $H_{1}$, defines a trend in the series at the chosen significance level $(\alpha)$ and data increase or decrease with the chronological order number (i) $[36,43]$. This test performed on the basis of time series data are identically distributed and independent. The test statistics $R_{s p}$ is given by the following equation:

$$
R_{s p}=1-\frac{6 \sum_{i=1}^{n}\left(D_{i}-i\right)^{2}}{n\left(n^{2}-1\right)}
$$

where $D_{i}$ is the $i$ th observation rank, $i$ is the chronological order number, and $n$ is the total length of the time series data. The standardized statistics $Z_{s p}$ is given by equation (6), where $Z_{s p}$ is the student's $t$-distribution with $(n-2)$ degrees of freedom [44]:

$$
Z_{s p}=R_{s p} \sqrt{\frac{n-2}{1-R_{s p}^{2}}},
$$

where (+ve) $Z_{s p}$ indicates an increasing trend and (-ve) $Z_{s p}$ indicates a decreasing trend. From Student's $t$-distribution table, the critical value of $t$ at a 0.05 significance level is defined as $t_{(n-2,1-(\alpha / 2))}$ [44]. The null hypothesis $\left(H_{0}\right)$ is rejected, indicating a significant trend in the time series if $\left|Z_{s p}\right|>t_{(n-2,1-(\alpha / 2))}$.

\section{Sen's Slope Estimation Test}

Sen's slope estimator test is used to compute the magnitude of a temporal trend, and it is widely used in analysis of rainfall patterns [43, 45-47]. The slope for data pairs are calculated using the following equation:

$$
d_{k}=\frac{X_{j}-X_{k}}{j-i},
$$

where $X_{j}$ and $X_{k}$ correspond to the data values at time $j$ and $k$, respectively. Sen's slope $Q_{i}$ is given by equation (8), and positive $Q_{i}$ values indicate an increasing (upward) trend, while negative values indicate the opposite:

$$
Q_{i}= \begin{cases}d_{(n+1) / 2}, & n \text { is odd } \\ \frac{1}{2}\left(d_{n / 2}+d_{(n+2) / 2}\right), & n \text { is even. }\end{cases}
$$

\section{Graphical Methods in Rainfall Trend Analysis}

Most of the data series are identified as serially independent in statistical analysis for trend detection. However, it is understood that some of the hydrological data are not, such that, at least during some time periods. Hence, these show significant serial correlation during statistical analysis [48]. Rathnayake [24] has quoted the possibility of error occurrence in trends even with moderate correlations, and limitations of these methods are mostly due to null hypothesis. Sen [49] has presented a simple, straightforward, and innovative graphical method to detect available positive or negative trend in climatic data. The following sequence of steps proposes the methodology for this graphical method:

(1) Initially, two or more equal subseries are created by dividing the main data series

(2) Then, these new subseries are arranged in the ascending order

(3) Next, two antecedent series are plotted in the Cartesian coordinate system, where older one is slotted to the $X$ axis and recent series in the $Y$ axis

(4) Following, $Y=X$ graph and $\pm 5 \%$ lines are plotted in the same Cartesian coordinate system

(5) It is deemed that there is no trend, if the time series is scattered in between $+5 \%$ and $-5 \%$ lines. If data are scattered above $+5 \%$ line, a positive trend in the recent data compared with older data can be detected and vice versa.

The percentage levels of $\pm 5 \%$ and $1 \%$ can be considered depending on the confidence level considered for plotting these graphs [50,51]. This graphical method is becoming famous among researchers [23, 24, 52-54].

\section{Case Study Application, Colombo District, Sri Lanka}

Rainfall data for 30 years were obtained from Meteorological Department of Sri Lanka for 10 different gauging stations located in the Colombo district from January 1989 to December 2018. Details of these rainfall stations are given in Table 1. However, the spatial distribution of the gauging stations can be seen from Figure 1. 
Missing rainfall data due to instrument or recording errors were filled using the normal ratio method. Then, the data were sorted according to monthly, annually, and seasonally. Sri Lanka has two major rainfall seasons (North-East Monsoonal Season (NEMS) and South-West Monsoonal Season (SWMS)). These monsoons are usually active for the months of December to February (NEMS) and May to September (SWMS). In addition, it receives rainfall from two intermediate seasons: First Inter Monsoon (FIMS; March and April) and Second Inter Monsoon (SIMS; October and November). However, Colombo receives most of its rainfall from SWMS.

\section{Results}

Prior to analysis of the data, it is customary to check the available meteorological data for their homogeneity. These test results for monthly rainfall data show that at 5\% significance, they are homogeneous under Pettitt, SNHT test, Buishand, and von Neumann methods for majority of stations. However, the SNHT test for Dehiwala and Padukka showed nonhomogeneity results while the von Neumann test showed nonhomogeneity for Homagama station.

Table 2 tabulates the summary of the trend analysis results from the MannKendall test (MK), Spearmen's Rho test (SR), and Graphical method (GM) for trend detection at $5 \%$ and $1 \%$ significance for ten selected stations located in the Colombo district. Based on the results in the table, it is visible that the two statistical trend analysis methods showcase similar observations at both $5 \%$ and $1 \%$ significances. However, little difference can be observed from MK test to SR test with no trends for Dehiwala and Padukka station at $1 \%$ significance level. Nevertheless, both locations showed trends at 5\% significance level. Therefore, that should be further investigated with more research. Geometrical analysis shows some comparable results to the two statistical methods in identifying rainfall trends. However, a detailed analysis on this graphical method is given with Figure 2.

Figure 2 shows the results of the graphical method. The straight lines of each plot show the $45^{\circ}(1: 1)$ relationships. In addition, the dashed lines represent the $\pm 5 \%$ variance lines. Potential trends in the rainfall of first half of time series compared to second half are shown through scattered data points. Thus, it is clear that an upward trend is available for Padukka station as shown in the Figure 2(i). Even though some data scatter for a positive trend is visible in the plot Figure 2(d), conclusive evidence is unavailable to derive a trend. Apart from these, no trend could be detected through other plots since data scatters are either between dashed (variance of $1: 1$ ) lines or much closer to them. The predicted upward trend in Padukka station is confirmed by the statistical analysis results of the MannKendall test and Spearman's Rho test as given in Table 2. As previously discussed, clear evidences are unavailable from the graphical method to show the trend detected from MK and SR tests for Dehiwala station for annual rainfall.

Table 3 summarizes the comparison results of the identified trends for seasonal rainfalls in the 10 rainfall
TABle 1: Details of the selected weather stations of Colombo district.

\begin{tabular}{lcc}
\hline Weather station & Location & Altitude $(\mathrm{m})$ \\
\hline Colombo & $6.90 \mathrm{~N}, 79.87 \mathrm{E}$ & 12 \\
Angoda & $6.93 \mathrm{~N}, 79.92 \mathrm{E}$ & 15 \\
Avissawella & $6.92 \mathrm{~N}, 80.18 \mathrm{E}$ & 69 \\
Dehiwala & $6.85 \mathrm{~N}, 79.87 \mathrm{E}$ & 16 \\
Hanwella & $6.88 \mathrm{~N}, 80.12 \mathrm{E}$ & 16 \\
Homagama & $6.93 \mathrm{~N}, 80.02 \mathrm{E}$ & 11 \\
Labugama & $6.83 \mathrm{~N}, 80.18 \mathrm{E}$ & 60 \\
Oruwala & $6.88 \mathrm{~N}, 80.00 \mathrm{E}$ & 16 \\
Padukka & $6.82 \mathrm{~N}, 80.12 \mathrm{E}$ & 27 \\
Rathmalana & $6.82 \mathrm{~N}, 79.88 \mathrm{E}$ & 9 \\
\hline
\end{tabular}

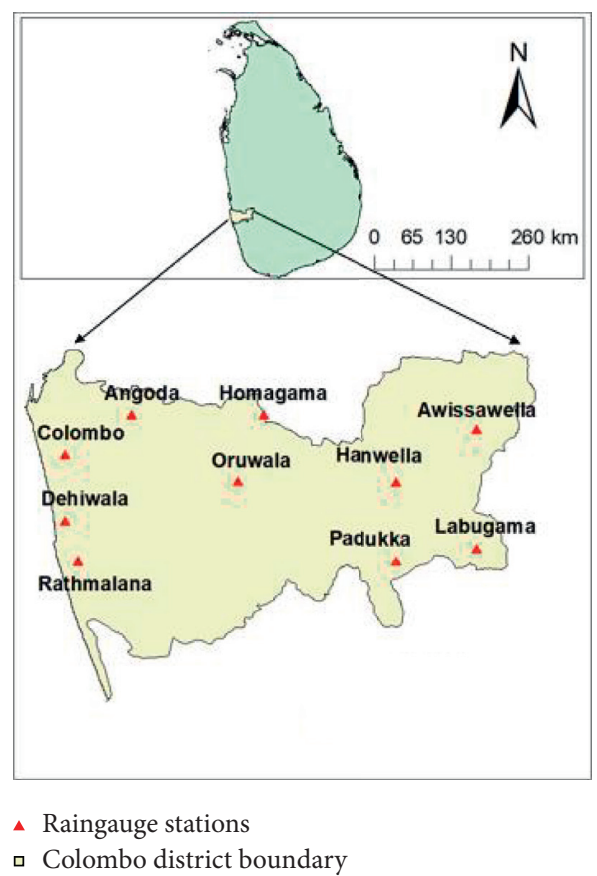

FIgURE 1: Locations of selected rain gauges in Colombo district.

stations. It only shows the stations with an identified trend. The nonstated stations in Table 3 have not shown any trends from the methods those were tested. Therefore, in other words, it can be concluded that those results are comparable with each other for the 3 methods. 100\% match can be seen in Colombo (for NEMS) and in Padukka (for FIMS) as shown in Table 3. However, for others, a mixed conclusion can be drafted here. In most of the cases, at least two methods have shown a trend to the seasonal rainfall.

Two plots for Padukka for graphical method for seasonal rainfall are presented in Figure 3. These two are showcased here as an example. Some of the outliers are found in these two plots. Even though both plots were analyzed as upward trends, two data points in each plot were placed under the $-5 \%$ line. These can be considered the outliers. However, a careful concern should be given when ignoring these outliers.

Similar results can be observed in seasonal rainfall trend comparison when the MK and SR methods were considered 
TABLE 2: Trend analysis results for annual rainfall.

\begin{tabular}{|c|c|c|c|}
\hline \multirow{2}{*}{ Station } & \multirow{2}{*}{ Test } & \multicolumn{2}{|c|}{ Annual rainfall } \\
\hline & & $5 \%$ significance & $1 \%$ significance \\
\hline Dehiwala & $\begin{array}{c}\text { MK and Sen's } \\
\text { SR } \\
\text { GM } \\
\end{array}$ & $\begin{array}{c}\text { Upward trend }(18.63 \mathrm{~mm} / \text { year }) \\
\text { Upward trend }(18.63 \mathrm{~mm} / \text { year }) \\
\text { No trend }\end{array}$ & $\begin{array}{c}\text { No trend } \\
\text { Upward trend }(18.63 \mathrm{~mm} / \text { year }) \\
\text { No trend }\end{array}$ \\
\hline Padukka & $\begin{array}{c}\text { MK and Sen's } \\
\text { SR } \\
\text { GM } \\
\end{array}$ & $\begin{array}{c}\text { Upward trend }(62.24 \mathrm{~mm} / \text { year }) \\
\text { Upward trend }(62.24 \mathrm{~mm} / \text { year }) \\
\text { Upward trend }\end{array}$ & $\begin{array}{c}\text { No trend } \\
\text { Upward trend }(62.24 \mathrm{~mm} / \text { year }) \\
\text { Upward trend }\end{array}$ \\
\hline Rathmalana & $\begin{array}{c}\text { MK and Sen's } \\
\text { SR } \\
\text { GM } \\
\end{array}$ & $\begin{array}{l}\text { No trend } \\
\text { No trend } \\
\text { No trend }\end{array}$ & $\begin{array}{l}\text { No trend } \\
\text { No trend } \\
\text { No trend }\end{array}$ \\
\hline Colombo & & No trend for any method & No trend for any method \\
\hline Angoda & & No trend for any method & No trend for any method \\
\hline Avissawella & & No trend for any method & No trend for any method \\
\hline Hanwella & & No trend for any method & No trend for any method \\
\hline Homagama & & No trend for any method & No trend for any method \\
\hline Labugama & & No trend for any method & No trend for any method \\
\hline Oruwala & & No trend for any method & No trend for any method \\
\hline
\end{tabular}

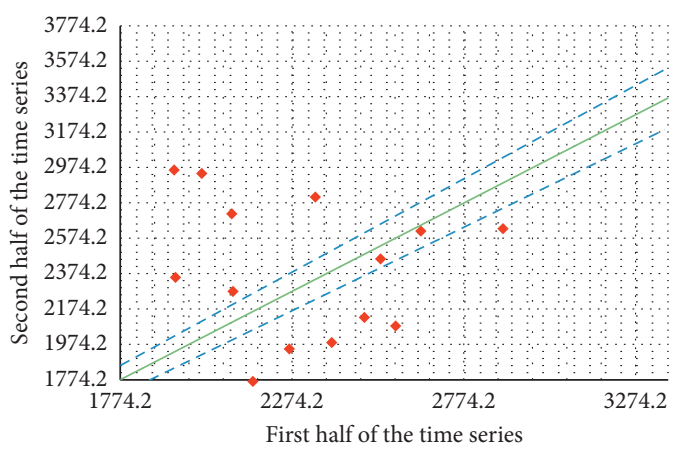

(a)

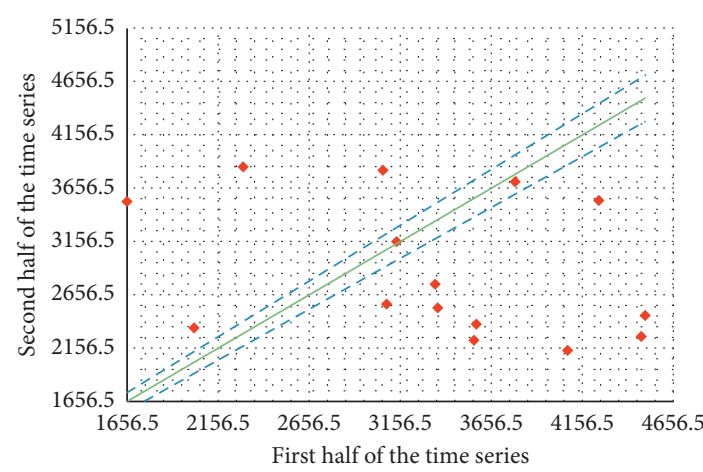

(c)

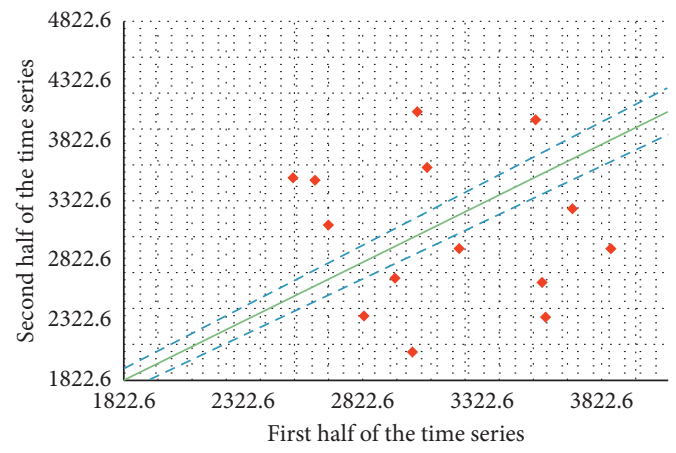

(e)

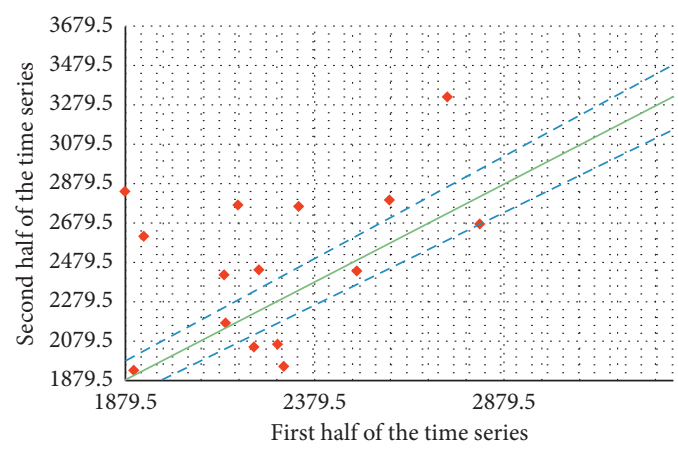

(b)

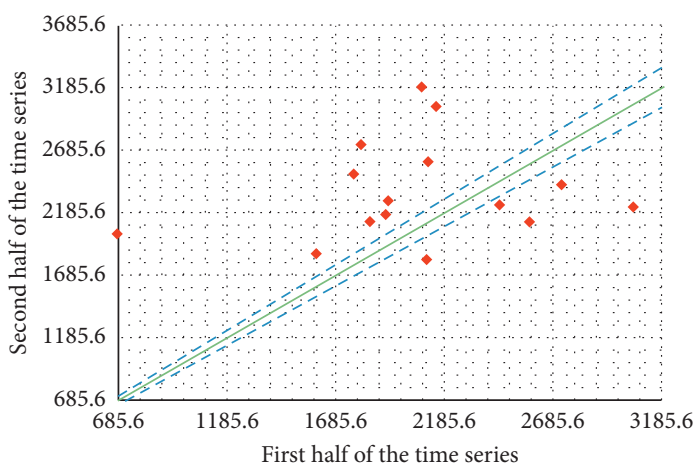

(d)

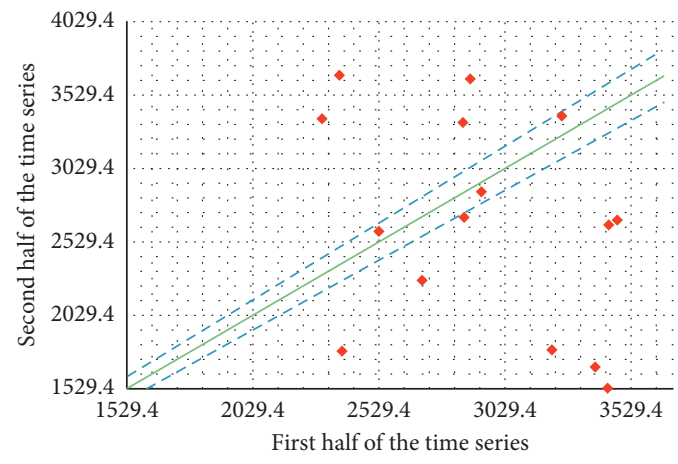

(f)

Figure 2: Continued. 


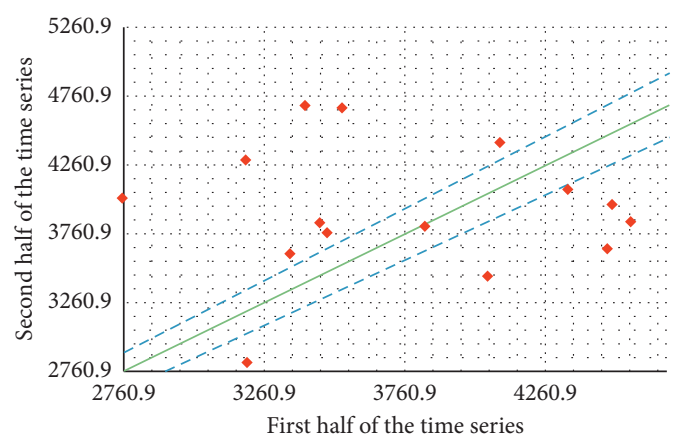

(g)

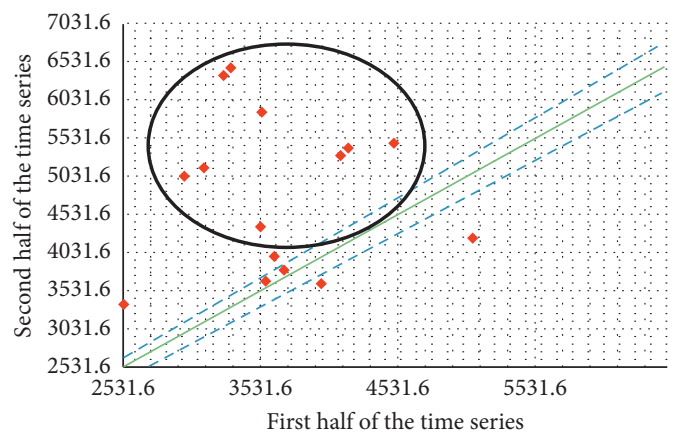

(i)

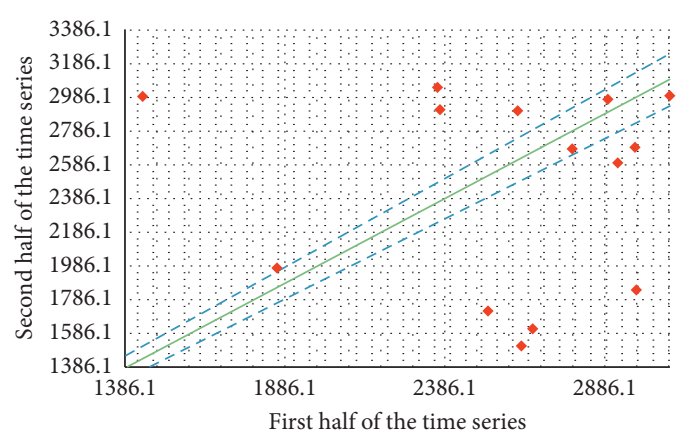

(h)

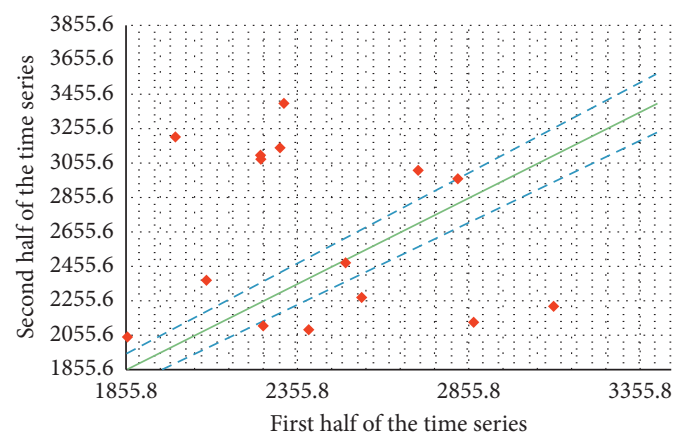

(j)

Figure 2: Graphical trends for annual rainfall. (a) Colombo. (b) Angoda. (c) Avissawella. (d) Dehiwala. (e) Hanwella. (f) Homagama. (g) Labugama. (h) Oruwala. (i) Padukka. (j) Rathmalana.

TABLE 3: Trend analysis results for seasonal rainfall variation at 5\% significance level.

\begin{tabular}{lcccc}
\hline Station & Season & & & Test \\
SR & UK & Upward trend $(7.39 \mathrm{~mm})$ & Upward trend \\
\hline Colombo & NEMS & Upward trend $(7.39 \mathrm{~mm})$ & Downward trend $(12.33 \mathrm{~mm})$ & Downward trend \\
\hline Avissawella & SWMS & No trend & Upward trend $(7.39 \mathrm{~mm})$ & No trend \\
\hline Dehiwala & NEMS & Upward trend $(8.57 \mathrm{~mm})$ & Upward trend $(8.20 \mathrm{~mm})$ & No trend \\
\hline Labugama & FIMS & No trend & Upward trend $(7.16 \mathrm{~mm})$ & No trend \\
\hline Oruwala & NEMS & Upward trend $(7.16 \mathrm{~mm})$ & Upward trend $(10.23 \mathrm{~mm})$ & No trend \\
\hline & NEMS & No trend & Upward trend $(18.52 \mathrm{~mm})$ & Upward trend \\
Padukka & FIMS & Upward trend $(18.52 \mathrm{~mm})$ & Upward trend $(22.85 \mathrm{~mm})$ & No trend \\
& SWMS & No trend & Upward trend $(11.22 \mathrm{~mm})$ & Upward trend \\
\hline
\end{tabular}

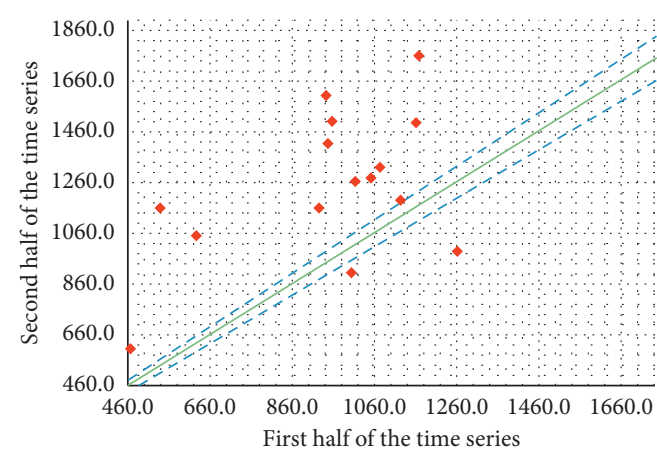

(a)

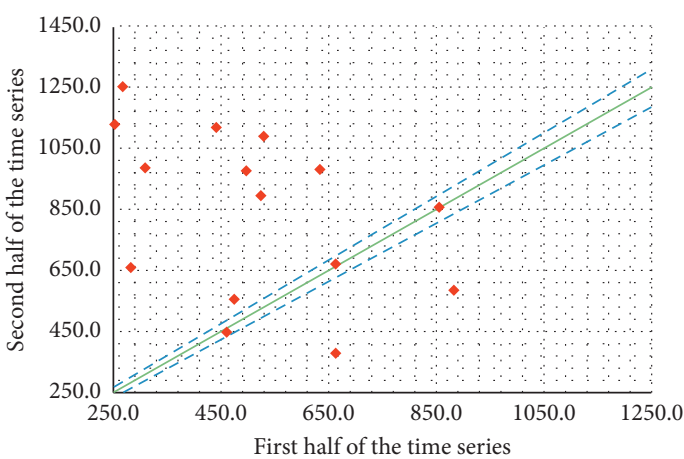

(b)

FIGURE 3: Trend analysis results using the graphical method for seasonal rainfall for Padukka (a) in SIMS and (b) in FIMS. 
TABLE 4: Trend analysis results for monthly variation at $5 \%$ significance level.

\begin{tabular}{lcccc}
\hline Station & Month & MK & SR & GM \\
\hline Colombo & July & Downward trend $(2.87 \mathrm{~mm})$ & Downward trend $(2.87 \mathrm{~mm})$ & No trend \\
Angoda & July & Downward trend $(3.60 \mathrm{~mm})$ & Downward trend $(3.60 \mathrm{~mm})$ & DW trend \\
Avissawella & July & Downward trend $(4.91 \mathrm{~mm})$ & Downward trend $(4.91 \mathrm{~mm})$ & No trend \\
Dehiwala & February & Upward trend $(2.85 \mathrm{~mm})$ & Upward trend $(2.85 \mathrm{~mm})$ & No trend \\
Hanwella & July & Downward trend $(5.05 \mathrm{~mm})$ & Downward trend $(5.05 \mathrm{~mm})$ & No trend \\
\hline
\end{tabular}

at $1 \%$ significance level. Gauging stations Angoda, Dehiwala, Hanwella, Homagama, Oruwala, Labugama, and Rathmalana have not shown rainfall trend. However, interestingly, some of the rainfall trends shown in 5\% significant levels have disappeared in the $1 \%$ significant level. For example, Colombo has shown an upward trend in NEMS for 5\% significance level; however, it has not shown any trend in $1 \%$ significance level. This is interesting, and therefore, further investigation is required in this case. Similar cases can be found in Avissawella and Padukka too.

Monthly trend analysis and its comparison show some interesting results. Comparable results were obtained for several stations for both monthly and seasonally rainfall trends. For example, Avissawella has downward trends in the month of July whereas it was reflected in the southwestern monsoon season (SWMS). Labugama, Oruwala, and Padukka show the similar results. However, contrasting results are observed in Colombo rainfall trends. It has an upward trend in northeastern monsoon season (NEMS), while having a downward trend in July. However, these two are not in the same time periods.

Nevertheless, an interesting observation was found in the month of July for many stations (Colombo, Angoda, Avissawella, Hanwella, Homgama, Labugama, Oruwala, and Rathmalana). July where Colombo is under the heavy rainfall shows a downward rainfall trend. As a district in the wet zone and frequent floods occurring in the southwestern monsoon time, this downward trend might be a positive scenario to see with. However, a detailed scientific discussion has to be conducted for further findings. However, comparable results were obtained for most of the stations in the monthly rainfall trends in three methods. Few of the results in the scale of month for some of the stations can be seen in Table 4 .

\section{Discussion}

Several comparison studies of rainfall trends can be observed in the literature. However, only two studies were found in the context of Sri Lanka. Rathnayake [24] has investigated two catchments in Sri Lanka (Denawaka Ganaga and Uma Oya catchments) in the context of rainfall trend analysis and compared the nonparametric MK test with the innovative graphical trend analysis method. It was concluded that the graphical method can be easily adopted to identify the rainfall trends qualitatively but not quantitatively. In addition, Nisansala et al. [23] analyzed 24 rain gauging stations around Sri Lanka and compared the rainfall trend analysis with MK test results against graphical methods (Innovative Trend Analysis (ITA)) and Spearman's rho test. They have found that there is a positive correlation in between the trend analysis results of MK test and ITA using Spearman's rho correlation coefficient. In addition, they have found $80 \%$ of agreement of graphical trend analysis results to the MK test results. Therefore, they have concluded that the graphical method can be less complicatedly used in identification of the rainfall trends.

As it was stated in Section 8, a downward rainfall trend was identified in the month of July in Colombo. This was supported by the annual scale in Nissansala et al. [23]. Nevertheless, Jayawardene et al. [17] have contrasting results from the $\mathrm{MK}$ test. They have found a positive rainfall trend in Colombo in the annual scale. More importantly, they have analyzed rainfall data from 1869 to 1998 for this conclusion, whereas Nisansala et al. [23] have used 1987 to 2017 recent rainfall data. Therefore, the test scales are different and incomparable. Hence, it would be interesting to observe the rainfall in Colombo for the coming years while analyzing them in the month of July.

Zhang et al. [55] have carried out the trend analysis not only to rainfall but also to identify the trends in droughts. They have compared the results in between MK test and Speaman's rho test and concluded that comparable results can be found in both techniques. Ahmad et al. [43] and SatishKumar and Rathnam [56] are couple of more examples of the same findings and conclusions.

Similar results were found in this research presented in this paper. It was well found that the results from Spearman's rho test and MK test match well not only in trend identification but also in magnitude of trends. Similarly, graphical analyses show the comparable results, however, not to $100 \%$. This was well discussed by the previous researchers $[23,24]$. Therefore, similar conclusions are drafted from this research. Caloiero et al. [57] and Gedefaw et al. [58] have supporting research to the above stated idea. They have concluded that graphical methods are easy to use; however, they should be used carefully.

However, researchers have found contrasting results among some of the methods. Ay [51] has stated that contrasting results in between the MK test and Sen's trend test from the results obtained in Turkey. In addition to the rainfall, the temperature trend was also investigated in this research. Nevertheless, the MK test is widely accepted as a reliable test to identify the climatic trends. Therefore, the research findings in nonparametric tests ( $\mathrm{MK}$ test) in this research paper are considered reliable. Thus, the trend analysis to the capital city of Colombo and surroundings will be important in future water resource management and planning. 


\section{Conclusions}

Comparison of three climatic trend analyses (MannKendall test, Spearman's rho test, and graphical test) was carried out in this paper. The rainfall trends obtained from these three results were compared with each other for 10 rainfall stations in Colombo. Three resolution levels, including annual, seasonal, and monthly rainfall, were tested under the three methods. Trend analysis results conclude that these three methods produce comparable results. The MannKendall test and Spearman's rho tests produce almost similar trends with trend magnitudes. However, the graphical method sometimes produced contrasting results compared with other two nonparametric tests. Therefore, it can be concluded herein that careful use of the graphical method is essential in important planning related work. In addition, it is always better to consider another trend analysis approach with the graphical method; thus, there is always a comparison of results. This process leads to better achievements. Nevertheless, it was found that the month July is critical for Colombo as it has downward rainfall trends for significant number of rain gauges. July is one of the months in which Colombo receives its major rainfall; therefore, careful planning is essential.

\section{Data Availability}

The climatic data and the analysis data are available from the corresponding author upon request.

\section{Disclosure}

The research was carried out in the Sri Lanka Institute of Information Technology environment.

\section{Conflicts of Interest}

The authors declare that they have no conflicts of interest. The first three authors are working as research assistants in the corresponding author's research group. The corresponding author is a senior lecturer in the Faculty of Engineering, Sri Lanka Institute of Information Technology, Sri Lanka.

\section{Acknowledgments}

The authors are grateful to the Sri Lanka Institute of Information Technology, Sri Lanka, for providing financial support to carry out this research.

\section{References}

[1] L. Manawadu and N. Fernando, "Climate changes in Sri Lanka," in Proceedings of the Annual Research Symposium, pp. 1-26, Colombo, Sri Lanka, November 2008.

[2] C. Parmesan and G. Yohe, "A globally coherent fingerprint of climate change impacts across natural systems," Nature, vol. 421, pp. 37-42, 2003.

[3] K. P. Sharma, B. MooreIII, and C. J. Vorosmarty, "Anthropogenic, climatic, and hydrologic trends in the Kosi Basin, Himalaya," Climatic Change, vol. 47, pp. 141-165, 2000.
[4] T. Lebel and A. Ali, "Recent trends in the central and western Sahel rainfall regime (1990-2007)," Journal of Hydrology, vol. 375, no. 1-2, pp. 52-64, 2009.

[5] K. E. Trenberth, "The impact of climate change and variability on heavy precipitation, floods, and droughts," in Encyclopedia of Hydrological SciencesJohn Wiley, Chichester, UK, 2008.

[6] I. Hassan, R. M. Kalin, J. A. Aladejana, and C. J. White, "Potential impacts of climate change on extreme weather events in the Niger delta part of Nigeria," Hydrology, vol. 7, no. 1, p. 19, 2020.

[7] F. De Paola, M. Giugni, F. Pugliese, A. Annis, and F. Nardi, "GEV parameter estimation and stationary vs. non-stationary analysis of extreme rainfall in African test cities," Hydrology, vol. 5, no. 2, p. 28, 2018.

[8] J. E. Bullard, A. Ockelford, C. L. Strong, and H. Aubault, "Impact of multi-day rainfall events on surface roughness and physical crusting of very fine soils," Geoderma, vol. 313, pp. 181-192, 2018.

[9] S. Nandargi, A. Gaur, and S. S. Mulye, "Hydrological analysis of extreme rainfall events and severe rainstorms over Uttarakhand, India," Hydrological Sciences Journal, vol. 61, no. 12, pp. 2145-2163, 2016.

[10] H. J. Fowler and C. G. Kilsby, "Implications of changes in seasonal and annual extreme rainfall," Geophysical Research Letters, vol. 30, 2003.

[11] M. Brunet and P. Jones, "Data rescue initiatives: bringing historical climate data into the 21 st century," Climate Research, vol. 47, no. 1, pp. 29-40, 2011.

[12] N. Nandakumar and R. G. Mein, "Uncertainty in rainfallrunoff model simulations and the implications for predicting the hydrologic effects of land-use change," Journal of $\mathrm{Hy}$ drology, vol. 192, no. 1-4, pp. 211-232, 1997.

[13] A. Kosanic, S. Harrison, K. Anderson, and I. Kavcic, "Present and historical climate variability in South west england," Climatic Change, vol. 124, no. 1-2, pp. 221-237, 2014.

[14] I. T. Ekeu-wei, "Evaluation of hydrological data collection challenges and flood estimation uncertainties in Nigeria," Environment and Natural Resources Research, vol. 8, no. 2, pp. 44-54, 2018.

[15] J. M. Colston, T. Ahmed, C. Mahopo et al., "Evaluating meteorological data from weather stations, and from satellites and global models for a multi-site epidemiological study," Environmental Research, vol. 165, pp. 91-109, 2018.

[16] N. Alahacoon, K. Matheswaran, and P. Pani, "A decadal historical satellite data and rainfall trend analysis (2001-2016) for flood hazard mapping in Sri Lanka," Remote Sens, vol. 10, pp. 16-23, 2018.

[17] H. Jayawardene, D. Sonnadara, and D. Jayewardene, "Trends of rainfall in Sri Lanka over the last century," Sri Lankan Journal of Physics, vol. 6, p. 7, 2005.

[18] S. Herath and U. Ratnayake, "Monitoring rainfall trends to predict adverse impacts-a case study from Sri Lanka (1964-1993)," Global Environmental Change, vol. 14, pp. 71-79, 2004.

[19] I. M. S. P. Jayawardena, D. W. T. T. Darshika, and H. M. R. Herath, "Recent trends in climate extreme indices over Sri Lanka," American Journal of Climate Change, vol. 7, no. 4, pp. 586-599, 2018.

[20] G. Naveendrakumar, M. Vithanage, H.-H. Kwon, M. C. M. Iqbal, S. Pathmarajah, and J. Obeysekera, "Five decadal trends in averages and extremes of rainfall and temperature in Sri Lanka," Advances in Meteorology, vol. 2018, Article ID 4217917, 13 pages, 2018. 
[21] B. A. Malmgren, R. Hulugalla, Y. Hayashi, and T. Mikami, "Precipitation trends in Sri Lanka since the 1870s and relationships to El Niño-southern oscillation," International Journal of Climatology, vol. 23, no. 10, pp. 1235-1252, 2003.

[22] A. Thevakaran, R. Suppiah, and U. Sonnadara, "Trends in extreme rainfall events in Sri Lanka, 1961-2010," Journal of the National Science Foundation of Sri Lanka, vol. 47, no. 3, pp. 285-295, 2019.

[23] W. D. S. Nisansala, N. S. Abeysingha, A. Islam, and A. M. K. R. Bandara, "Recent rainfall trend over Sri Lanka (1987-2017)," International Journal of Climatology, vol. 40, no. 7, pp. 3417-3435, 2019.

[24] U. Rathnayake, "Comparison of statistical methods to graphical methods in rainfall trend analysis: case studies from tropical catchments," Advances in Meteorology, vol. 2019, Article ID 8603586, 10 pages, 2019.

[25] H. Alexandersson, "A homogeneity test applied to precipitation data," Journal of Climatology, vol. 6, no. 6, pp. 661-675, 1986.

[26] H. M. Kang and F. Yusof, "Homogeneity tests on daily rainfall series in peninsular Malaysia," International Journal of Contemporary Mathematical Sciences, vol. 7, pp. 9-22, 2012.

[27] N. O. S. Alghazali and D. A. H. Alawadi, "Testing the Homogeneity of rainfall records for some stations in Iraq," International Journal of Civil Engineering and Technology, vol. 5, pp. 76-87, 2014.

[28] A. M. Al-lami, Y. K. Al-timimi, and A. M. Al-salihi, "The homogeneity analysis of rainfall time series for selected meteorological stations in Iraq," Diyala Journal For Pure Science, vol. 10, pp. 60-77, 2014.

[29] O. M. A. M. Agha, S. Ç. Bağçacı, and N. Şarlak, "Homogeneity analysis of precipitation series in north Iraq," IOSR Journal of Applied Geology and Geophysics, vol. 5, no. 3, pp. 57-63, 2017.

[30] H. Alexandersson and A. Moberg, "Homogenization of Swedish temperature data. Part I: homogeneity test for linear trends," International Journal of Climatology, vol. 17, no. 1, pp. 25-34, 1997.

[31] S. Sahin and H. K. Cigizoglu, "Homogeneity analysis of Turkish meteorological data set," Hydrological Processes, vol. 24, no. 8, pp. 981-992, 2010.

[32] J. B. Wijngaard, A. M. G. Klein Tank, and G. P. Können, "Homogeneity of 20th century European daily temperature and precipitation series," International Journal of Climatology, vol. 23, no. 6, pp. 679-692, 2003.

[33] A. Perera and U. Rathnayake, "Impact of climate variability on hydropower generation in an un-gauged catchment: erathna run-of-the-river hydropower plant, Sri Lanka," Applied Water Science, vol. 9, no. 3, p. 57, 2019.

[34] M. R. Haylock, N. Hofstra, A. M. G. Klein Tank, E. J. Klok, P. D. Jones, and M. New, "A European daily high-resolution gridded data set of surface temperature and precipitation for 1950-2006," Journal of Geophysical Research, vol. 113, 2008.

[35] D. R. Helsel and L. M. Frans, "Regional kendall test for trend," Environmental Science \& Technology, vol. 40, no. 13, pp. 4066-4073, 2006.

[36] S. Yue, P. Pilon, and G. Cavadias, "Power of the MannKendall and Spearman's rho tests for detecting monotonic trends in hydrological series," Journal of Hydrology, vol. 259, no. 1-4, pp. 254-271, 2002.

[37] D. H. Burn and M. A. H. Elnur, "Detection of hydrologic trends and variability," Journal of Hydrology, vol. 255, 2002.

[38] M. Brunetti, M. Maugeri, and T. Nanni, "Variations of temperature and precipitation in Italy from 1866 to 1995,"
Theoretical and Applied Climatology, vol. 65, no. 3-4, pp. 165-174, 2000.

[39] M. G. Kendall, Rank Correlation Methods, University of Michigan, Ann Arbor, MI, USA, 1975, ISBN 0852641990 9780852641996.

[40] R. M. Hirsch, J. R. Slack, and R. A. Smith, "Techniques of trend analysis for monthly water quality data," Water Resources Research, vol. 18, no. 1, pp. 107-121, 1982.

[41] E. Kahya and S. Kalayc1, "Trend analysis of streamflow in Turkey," Journal of Hydrology, vol. 289, no. 1-4, pp. 128-144, 2004.

[42] P. S. Porter, S. T. Rao, and C. Hogrefe, "Linear trend analysis: a comparison of methods," Atmospheric Environment, vol. 36, pp. 6-8, 2002.

[43] I. Ahmad, D. Tang, T. Wang, M. Wang, and B. Wagan, "Precipitation trends over time using mann-kendall and spearman's rho tests in Swat river basin, Pakistan," Advances in Meteorology, vol. 2015, Article ID 431860, 15 pages, 2015.

[44] E. R. Dahmen and M. J. Hall, Screening of Hydrological Data: Tests for Stationarity and Relative Consistency, Wageningen University, Wageningen, Netherlands, 1990.

[45] S. I. Sridhar and A. Raviraj, "Statistical trend analysis of rainfall in amaravathi river basin using Mann-Kendall test," Current World Environment, vol. 12, no. 1, pp. 89-96, 2017.

[46] P. K. Sen, "Estimates of the regression coefficient based on kendall's tau," Journal of the American Statistical Association, vol. 63, no. 324, pp. 1379-1389, 1968.

[47] K. R. Kumar, A. K. Sahai, K. K. Kumar et al., "High-resolution climate change scenarios for India for the 21st century," Current Science, vol. 90, pp. 334-345, 2006.

[48] S. Yue and C. Y. Wang, "Applicability of prewhitening to eliminate the influence of serial correlation on the mannkendall test applicability of prewhitening to eliminate the influence of serial correlation on the Mann-Kendall test," Water Resources Research, vol. 38, 2002.

[49] Z. Sen, "Innovative trend analysis methodology," Journal of Hydrologic Engineering, vol. 17, pp. 1042-1046, 2012.

[50] R. O. Ali and S. R. Abubaker, "Trend analysis using MannKendall, sen's slope estimator test and innovative trend analysis method in Yangtze river basin, China : review," International Journal of Engineering \& Technology, vol. 8, pp. 110-119, 2019.

[51] M. Ay, "Trend and homogeneity analysis in temperature and rainfall series in western black sea region, Turkey," Theoretical and Applied Climatology, vol. 139, no. 3-4, pp. 837-848, 2020.

[52] Y. Alifujiang, J. Abuduwaili, B. Emin, and M. Groll, "Innovative trend analysis of precipitation in the lake issyk-kul basin, Kyrgyzstan," Atmosphere, vol. 1, no. 4, pp. 332-347, 2020.

[53] Y. Wang, Y. Xu, H. Tabari et al., "Innovative trend analysis of annual and seasonal rainfall in the Yangtze River Delta, eastern China," Atmospheric Research, vol. 231, 2020.

[54] H. Wu and H. Qian, "Innovative trend analysis of annual and seasonal rainfall and extreme values in Shaanxi, China, since the 1950s," International Journal of Climatology, vol. 37, no. 5, pp. 2582-2592, 2016.

[55] Y. Zhang, W. Cai, Q. Chen, Y. Yao, and K. Liu, "Analysis of changes in precipitation and drought in aksu river basin, northwest China," Advances in Meteorology, vol. 2015, Article ID 215840, 15 pages, 2015.

[56] K. SatishKumar and E. V. Rathnam, "Comparison of six trend detection methods and forecasting for monthly groundwater levels-a case study," ISH Journal of Hydraulic Engineering, pp. 1-10, 2020. 
[57] T. Caloiero, R. Coscarelli, and E. Ferrari, "Analysis of monthly rainfall trend in calabria (southern Italy) through the application of statistical and graphical techniques," Proceedings, vol. 2, no. 11, pp. 629-637, 2018.

[58] M. Gedefaw, D. Yan, H. Wang et al., "Innovative trend analysis of annual and seasonal rainfall variability in Amhara regional state, Ethiopia," Atmosphere, vol. 9, no. 9, pp. 326-335, 2018. 